\title{
Preparation of Eri silk fibroin and gelatin blend film loaded chlorhexidine using as model for hydrophilic drug release
}

\author{
Yaowalak Srisuwan ${ }^{1}$, Nualchai Kotseang ${ }^{2}$, Komsan Namtaku $^{2}$, Wilaiwan Simchuer ${ }^{3}$, \\ Chirapha Butiman ${ }^{4}$, Prasong Srihanam ${ }^{1^{*}}$ \\ ${ }^{1}$ Department of Chemistry and Center of Excellence for Innovation in Chemistry, Mahasarakham University, Maha Sarakham, Thai- \\ land; ${ }^{*}$ Corresponding Author: prasong.s@msu.ac.th \\ ${ }^{2}$ Department of Science and Technology, Kalasin Rajabhat University, Kalasin, Thailand \\ ${ }^{3}$ Department of Chemistry, Loei Rajabhat University, Loei, Thailand \\ ${ }^{4}$ Silk Innovation Center, Mahasarakham University, Maha Sarakham, Thailand
}

Received 14 May 2012; revised 18 June 2012; accepted 30 June 2012

\begin{abstract}
The objective of this research was to prepare Eri silk fibroin solution for preparing silk film loaded chlorhexidine drug as model for hydrophilic drug release. The Eri silk cocoons were boiled in $0.5 \%$ $\mathrm{NaCO}_{3}$ solution at $90^{\circ} \mathrm{C}$, and then left in air dried at room temperature. The fibroin was dissolved in $9 \mathrm{M}\left(\mathrm{Ca}\left(\mathrm{NO}_{3}\right)_{2}\right)$ with ethanol (2 by mole) and heated at $70^{\circ} \mathrm{C}$. The silk fibroin (SF) solution was then dialyzed to exclude salt in phosphate buffer. The SF and gelatin (G) solutions were mixed for preparation of films in both with and without chlorhexidine. The films were observed their morphology under scanning electron microscope. The results found that all of films were rough of their surfaces, homogeneous texture without phase separation. The native SF film composed of pores throughout the film area but did not observe in native $G$ film. The results also showed that the SF and $G$ can be good interacted to form hydrogen bonds. These were indicated from FTIR spectra and thermal analysis. The chlorhexidine drug has not affect on the changes of film properties. However, the releasing pattern of chlorhexidine from each film was varied. The highest rate of drug releasing was found in the native SF film while the native $G$ film was the lowest. It might be suggested that the drug releasing rate was depended on polarity of each polymer components.
\end{abstract}

Keywords: Chlorhexidine; Gelatin; Fibroin; Film; Eri Silk; Drug Release

\section{INTRODUCTION}

Natural polymer is an important source for biotechno- logical development. In recent, biodegradable materials have been gradually used due to their suitable properties, especially biomedical or related fields [1]. Silk is a protein polymer. It has been used as biomedical material for a long history until the present [2]. Silk fibers most are belong to 2 families; bombycidae (domesticated) and saturniidae (wild) silks [3]. Each silk fiber composed of at least 2 main proteins which are fibroin, a core fibrous protein coated with sericin, a glue-like protein [4]. Silk can be modified into various forms depending on applications such as gel, powder, fiber, membrane, particle, sponge or film [5]. In two last decades, silk fibroin (SF) has been applied in various fields such as tissue engineering, regenerative medicine, gene therapy, controlled drug delivery and biotechnology [6]. These were due to its composed of many excellent properties including high mechanical, biocompatibility, biodegradability, water and vapor permeability and low-inflammatory response [7].

Another natural polymer chosen in this work is gelatin. The gelatin $(\mathrm{G})$ is a collagen derivative. Therefore, all most of its properties were the same as collagen. Gelatin has also used in various fields since it comprised of excellent properties like SF. Moreover, it is a low-cost production material. In the last 10 years, gelatin has been used as biomaterial for tissue engineering [8]. The results found that gelatin helps to increase of cell adhesion, migration and proliferation of many cells [9]. Moreover, gelatin has also applied in other fields such as controlled drug released, wound dressing, and health caring devices $[10,11]$. The gelatin can be used by itself or blended with other polymers [12].

Silk applications were found highly in B. mori, but little information about wild silk is available. In Thailand, Eri, a kind of wild silk, can rear and produce in a commercial level. It does not study as biomaterial for medical and pharmacological devices. In the present work, we 
have attempted to study the suitable method for preparing Eri SF solution and used the obtained SF solution as substrate to prepare SF/gelatin (G) blend films. The SF/G blend films were loaded with chlorhexidine which used as model of hydrophilic drug. The properties of the SF/G blend films as well as the releasing pattern of the drug from the films were also investigated and described.

\section{EXPERIMENTAL}

\subsection{Study of Suitable Condition for Dissolving SF}

SF solution can be prepared by cut the Eri cocoon into small pieces. They were then degummed to exclude sericin by boiling in $0.5 \% \mathrm{NaCO}_{3}$ solution at $90^{\circ} \mathrm{C}$. The extracts were performed for 2 times, each for $30 \mathrm{~min}$. The extracted silk was then washed with distilled water, before drying in an oven at $40^{\circ} \mathrm{C}$. The dried silk was dissolved by various kinds of solutions; $9 \mathrm{M} \mathrm{LiBr}, 9 \mathrm{M}$ $\mathrm{Ca}\left(\mathrm{NO}_{3}\right)_{2}, 9 \mathrm{M} \mathrm{ZnCl}_{2}, 9 \mathrm{M} \mathrm{LiSCN}, \mathrm{CaCl}_{2} /$ Ethanol $/ \mathrm{H}_{2} \mathrm{O}$ ( $3: 1: 8$ by mole) with the ratio of $1 \mathrm{~g}$ of silk/10 $\mathrm{ml}$ of solution. The temperatures were set from $70^{\circ} \mathrm{C}-90^{\circ} \mathrm{C}$, and time was arranged from $1-3 \mathrm{~h}$. The suitable condition was chosen and then takes the SF solution to dialyze against phosphate buffer using cellulose dialysis tube (Mw. Cut off $7500 \mathrm{kDa}$ ).

\subsection{Preparation of Gelatin Solution}

The gelatin solution was prepared as $1 \%(\mathrm{w} / \mathrm{v})$ which can be prepared by dissolving $1 \mathrm{~g}$ of gelatin powder in $100 \mathrm{ml}$ of distilled water. The mixture solution was then stirred until completely dissolved under room temperature.

\subsection{Preparation of SF/G Blend Films Loaded Chlorhexidine}

Many types of SF/G blend films were prepared as listed in Table 1. All of component was completely mixed. The $20 \mathrm{ml}$ of each mixture solution was then poured on the polystyrene plates. The plates were then dried in an oven at $40^{\circ} \mathrm{C}$ for 3 days.

Table 1. Composition of SF, G and drug for films preparation.

\begin{tabular}{cccc}
\hline $\mathrm{SF} / \mathrm{G}$ ratio (w/w) & $1 \% \mathrm{SF}(\mathrm{ml})$ & $1 \% \mathrm{G}(\mathrm{ml})$ & $\operatorname{Drug}(\mathrm{g})$ \\
\hline $3 / 0$ & 30 & 0 & 0.004 \\
$2 / 1$ & 20 & 10 & 0.004 \\
$1 / 1$ & 15 & 15 & 0.004 \\
$1 / 2$ & 10 & 20 & 0.004 \\
$0 / 3$ & 0 & 30 & 0.004 \\
\hline
\end{tabular}

\subsection{Morphological Observation}

All films were cut and observed under the scanning electron microscope (SEM) (JEOL, JSM-6460LV, Tokyo, Japan). The samples were sputter coated with gold by double side of carbon for enhancing surface conductivity.

\subsection{Secondary Structure Determination}

The secondary structures of the films were analyzed with FTIR (Perkin Elmer-Spectrum Gx, USA) in the spectral range of $2000-400 \mathrm{~cm}^{-1}$ at $4 \mathrm{~cm}^{-1}$ spectral resolution and 32 scans.

\subsection{Thermal Properties Analysis}

Thermal properties were measured using TA instruments, SDT Q600 (Luken's drive, New Castle, DE). The SF weight of $8-10 \mathrm{mg}$ were prepared and loaded in a platinum crucible. The samples were non-isothermal heated from $50^{\circ} \mathrm{C}$ to $800^{\circ} \mathrm{C}$ at a heating rate of $20^{\circ} \mathrm{C} / \mathrm{min}$. The TGA was carried out in nitrogen with the flow rate of $100 \mathrm{ml} / \mathrm{min}$. The TG and heat flow were recorded with TA Instrument's Q series explorer software. The analyses of the data were done using TA Instrument's Universal Analysis 2000 software (version 3.3B).

\subsection{In Vitro Study of Chlorhexidine Release}

$\mathrm{SF} / \mathrm{G}$ blend films loaded chlorhexidine were cut into $1.0 \mathrm{~cm}$ square shape before immersing in $20 \mathrm{ml}$ of phosphate buffer saline $\mathrm{pH}$ 7.4. The mixture was stirred continuously at $150 \mathrm{rpm}$ for $30 \mathrm{~min}$. The solution was collected in every designation time points and measured at $254 \mathrm{~nm}$ using UV-Vis spectrophotometer. After collection of solution, $20 \mathrm{ml}$ of fresh buffer was added. The study was extended for $48 \mathrm{~h}$ of immersion.

\section{RESULTS AND DISCUSSION}

Eri silk has limited for using except textile production. This was due to the Eri is a kind of wild silk which is very difficult prepared into solution. This was one reason for application Eri silk in other fields. Domesticated silk, $B$. mori has been reported about the solution that can be used for dissolving it such as $\mathrm{LiBr}[13,14]$ or $\mathrm{CaCl}_{2}$ with alcohol [15]. However, the solvent for dissolving of Eri $\mathrm{SF}$ is little information. Actually, domesticated and wild silks have different amino acid compositions and should be the reason of their different characteristics. B. mori composed of glycine in the highest ratio whereas alanine is the highest amino acid composed in wild silk.

\subsection{Suitable Condition Study for Dissolving Eri SF}

The suitable condition for dissolving Eri SF was con- 
sidered from the comparison of silk remaining and SF solution after using each designated conditions. The results found that Eri SF boiled in $9 \mathrm{M} \mathrm{Ca}\left(\mathrm{NO}_{3}\right)_{2}$ solution with ethanol ( 2 ratio by mol) at $70^{\circ} \mathrm{C}$ were the suitable condition.

\subsection{Morphological Observation}

SEM micrographs indicated that the native SF and $G$ have smooth surfaces and no phase separation. However, native SF film appeared the small pores cover the film area while the native $\mathrm{G}$ film has condensed texture and no pores were observed. In case of SF/G blend films, all ratios have smooth surfaces and no phase separation. As shown in Figure 1, increasing of gelatin help to increase the smooth surfaces of the film. Moreover, the blend films loaded chlorhexidine have negligible morphological difference when compared to the blend films without drug (Figure 2).
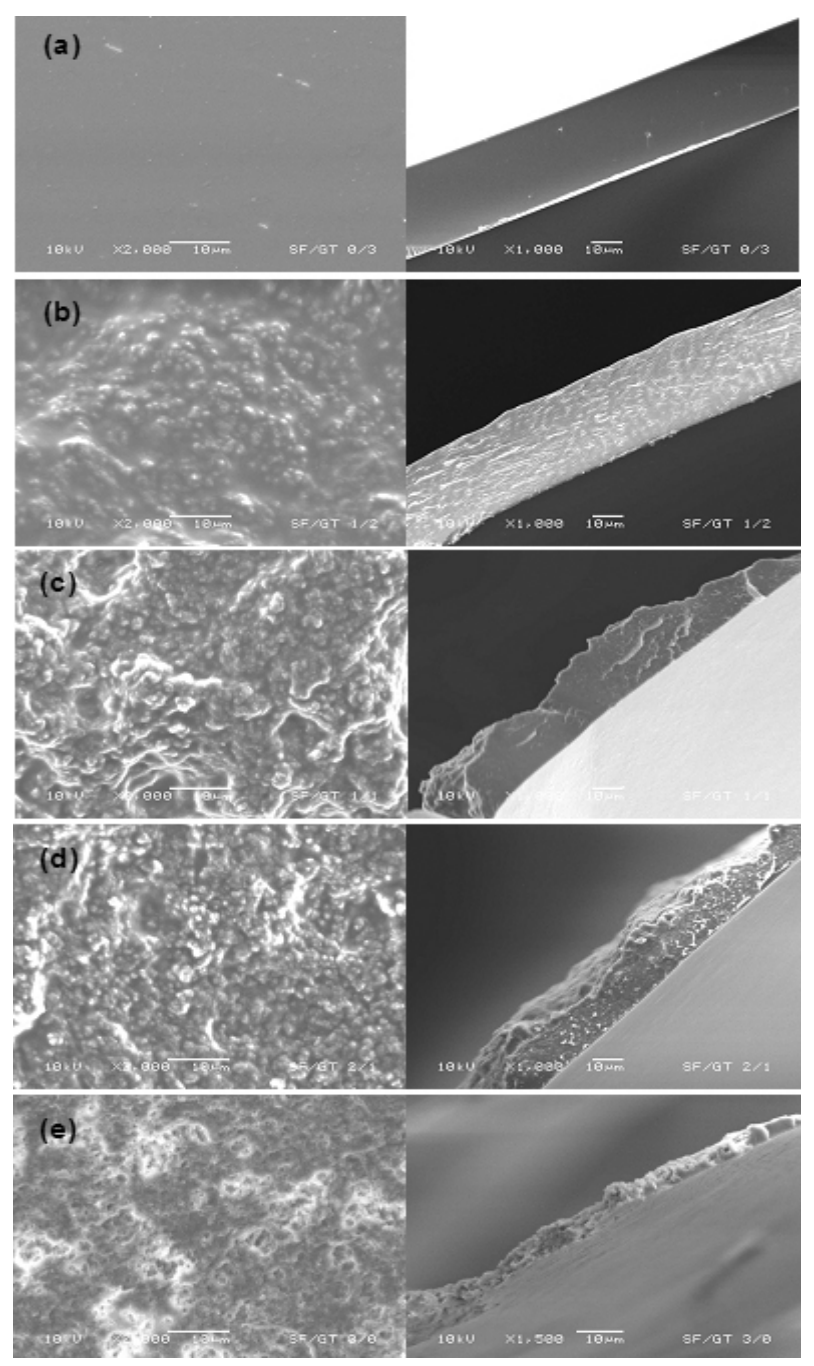

Figure 1. SEM micrographs of films prepared from different SF/G blend ratios without chlorhexidine: $3 / 0$ (a); 2/1 (b); 1/1 (c); $1 / 2$ (d) and 0/3 (e).
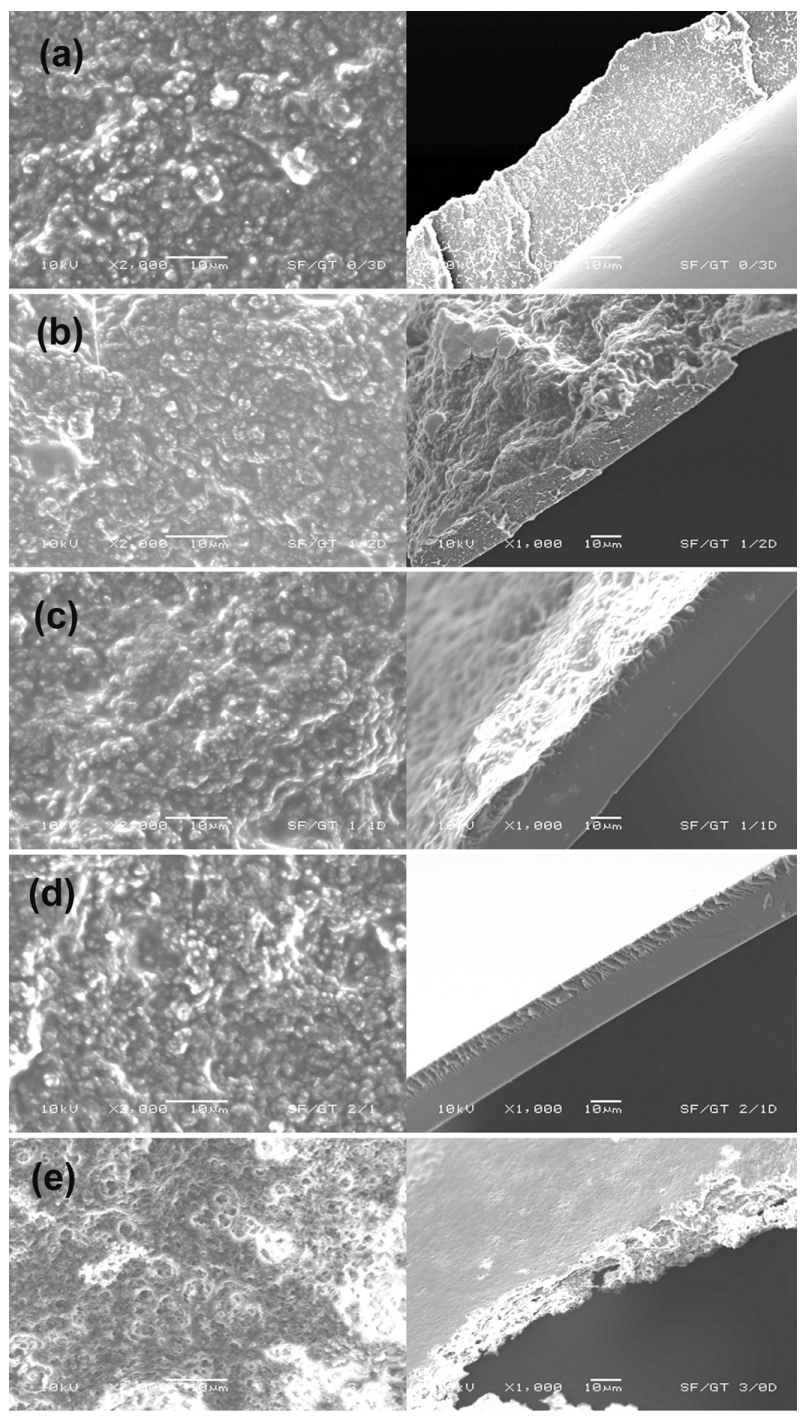

Figure 2. SEM micrographs of films prepared from different $\mathrm{SF} / \mathrm{G}$ blend ratios with chlorhexidine: $3 / 0$ (a); 2/1 (b); 1/1 (c); $1 / 2(d)$ and $0 / 3(e)$.

The SF/G blend films showed smooth surfaces indicated that SF and G have interacted together via bonding formation such as hydrogen bonds [10]. With the crosssection, the texture of the blend films has rough throughout the films. This might be reason from the amino acids compositions since the wild silk composed of high arginine and aspartic acids [16]. Both amino acids are hydrophilic and complicated structure than alanine or glycine. However, this texture should be advantaged for cell adhesion in tissue engineering, especially the sequence of arginine-glycine-aspartic acid (R-G-D) [17]. Moreover, this sequence dose not find in B. mori.

\subsection{Secondary Structure}

Secondary structures of films were investigated using FTIR. This technique is mostly used for protein struc- 
tural analysis. This was due to the functional group, amide, in the protein structures highly sensitive to infrared beam $[18,19]$. Generally, the main regions of amide were appeared at 3 points called amide I $\left(1700-1600 \mathrm{~cm}^{-1}\right)$, amide II (1600 - $\left.1500 \mathrm{~cm}^{-1}\right)$ and amide III (1300 - 1200 $\mathrm{cm}^{-1}$ ). As shown in Figures 3 and 4, the native fibroin film showed the absorption bands at 1678, 1655, 1615 $\mathrm{cm}^{-1}$ (amide I, $\mathrm{C}=\mathrm{O}$ stretching), 1559, $1522 \mathrm{~cm}^{-1}$ (amide II, N-H deformation) and $1240 \mathrm{~cm}^{-1}$ (amide III, C-N stretching). These mean the secondary structure of native SF films is crystalline with the mixture of $\alpha$-helix and $\beta$-sheet structures $[3,17]$. The native $\mathrm{G}$ film indicated the absorption bands at 1689, 1680, 1624, 1573, $1522(\mathrm{C}=\mathrm{O}$ stretching amide $\mathrm{I})$ and $1245 \mathrm{~cm}^{-1}(\mathrm{C}=\mathrm{O}$ stretching amide V), respectively. The absorption was from the carbonyl and amino groups in the gelatin structure. The $\mathrm{SF} / \mathrm{G}$ blend films showed the similar absorption bands like both native SF and G films, even with or without chlorhexidine. This result confirmed that the SF and G are interacted together via hydrogen bonds formation $[9,20]$.

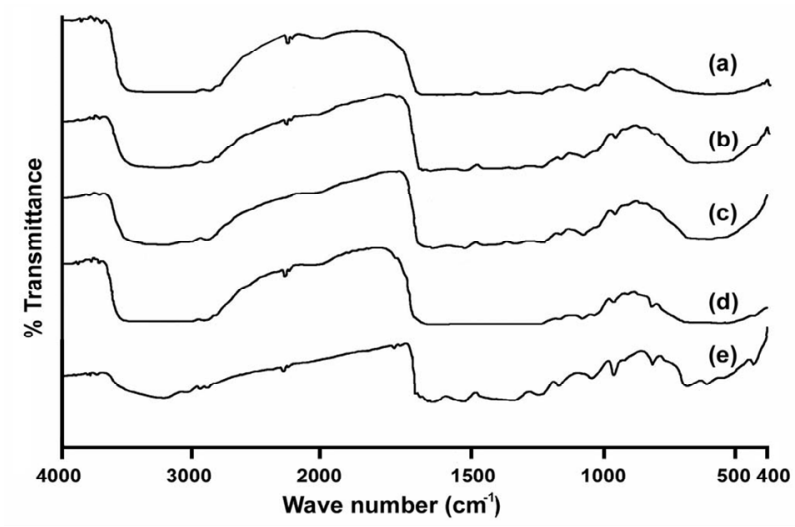

Figure 3. FTIR spectra of films prepared from different SF/G blend ratios without chlorhexidine: 0/3 (a); 1/2 (b); 1/1 (c); 2/1 (d) and 3/0 (e).



Figure 4. FTIR spectra of films prepared from different SF/G blend ratios with chlorhexidine: 0/3 (a); 1/2 (b); 1/1 (c); 2/1 (d) and $3 / 0(\mathrm{e})$.

\subsection{Thermal Properties}

Thermal properties of the films were analyzed using thermogravimetric analyzer (TG). The results found that all films did not completely decompose even at $800^{\circ} \mathrm{C}$ (Figures 5 and 6). The decomposition of films started at $200^{\circ} \mathrm{C}$, and has maximum decomposition temperature $\left(\mathrm{T}_{d, \max }\right)$ at the range of $300^{\circ} \mathrm{C}-400^{\circ} \mathrm{C}$ as dominantly shown by DTG curves (Figures 7 and 8). The native SF film has the maximum decomposition temperature at $322^{\circ} \mathrm{C}$ and $371^{\circ} \mathrm{C}$. This result related to previous study that the wild silk appeared the maximum decomposition temperature at least 2 steps [21]. The native gelatin has single of the $\mathrm{T}_{d, \max }$ at $336^{\circ} \mathrm{C}$. In the blend films, they indicated at least 2 steps of decomposition. This was due to the unique character of native $\mathrm{SF}$ and $\mathrm{G}$. The $\mathrm{T}_{d \text {,max }}$ of the blend films varied on the content of each polymer. The blend films loaded chlorhexidine showed similar of thermal properties as the film without drug (Figures 9 and 10). Heat flow curve of the native SF showed exo/endo

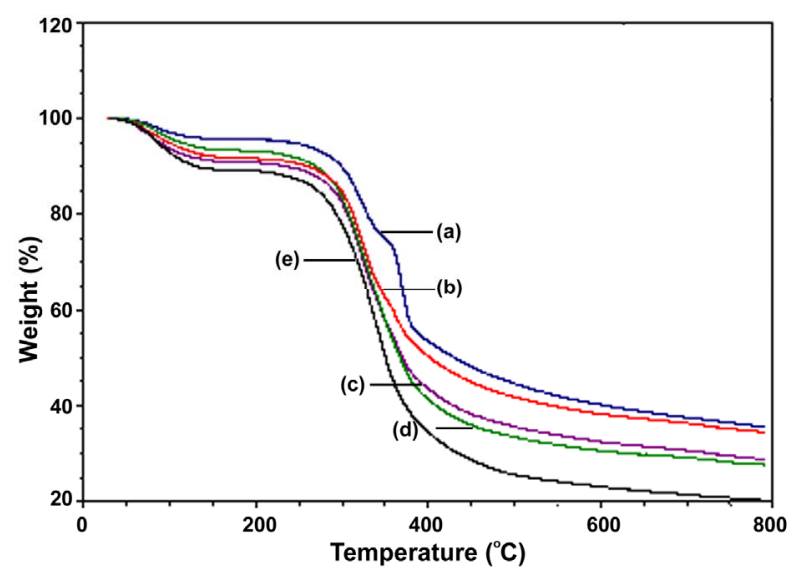

Figure 5. TG curves of films prepared from different $\mathrm{SF} / \mathrm{G}$ blend ratios without chlorhexidine: 3/0 (a); 2/1 (b); 1/1 (c); 1/2 (d) and $0 / 3$ (e).



Figure 6. TG curves of films prepared from different $S F / G$ blend ratios with chlorhexidine: 3/0 (a); 2/1 (b); 1/1 (c); 1/2 (d) and $0 / 3(\mathrm{e})$. 




Figure 7. DTG curves of films prepared from different $\mathrm{SF} / \mathrm{G}$ blend ratios without chlorhexidine: $3 / 0$ (a); $2 / 1$ (b); $1 / 1$ (c); $1 / 2$ (d) and $0 / 3(e)$.

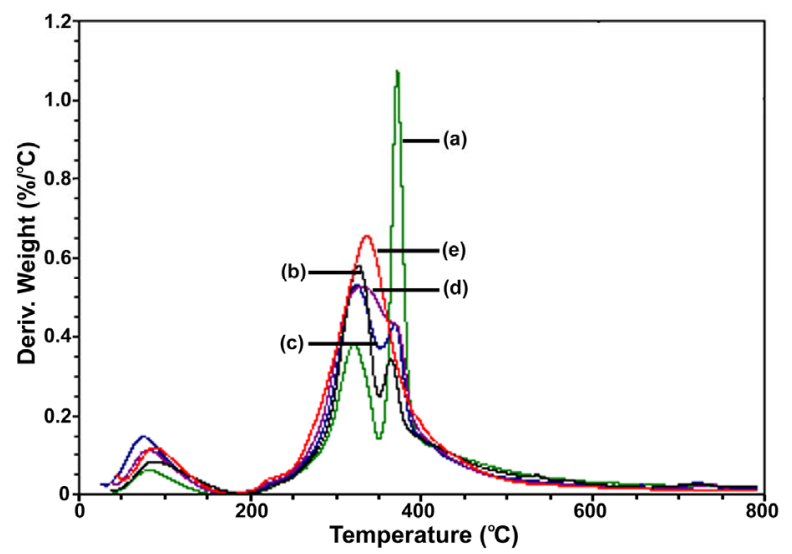

Figure 8. DTG curves of films prepared from different SF/G blend ratios with chlorhexidine: 3/0 (a); 2/1 (b); 1/1 (c); 1/2 (d) and $0 / 3(\mathrm{e})$.

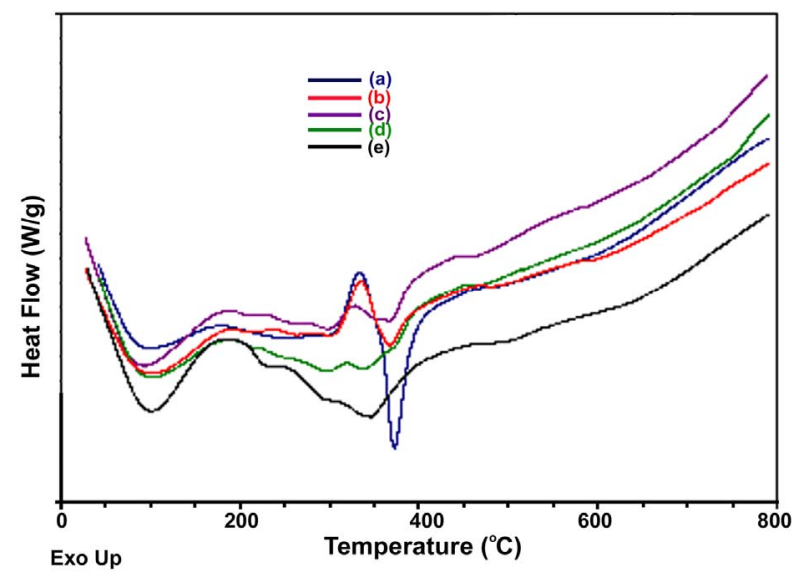

Figure 9. Heat flow curves of films prepared from different $\mathrm{SF} / \mathrm{G}$ blend ratios without chlorhexidine: $3 / 0$ (a); 2/1 (b); 1/1 (c); $1 / 2(\mathrm{~d})$ and $0 / 3(\mathrm{e})$.

thermic peaks at $334^{\circ} \mathrm{C}$ and $373^{\circ} \mathrm{C}$, respectively. The native gelatin film has exo/endo thermic peaks at $180^{\circ} \mathrm{C}$

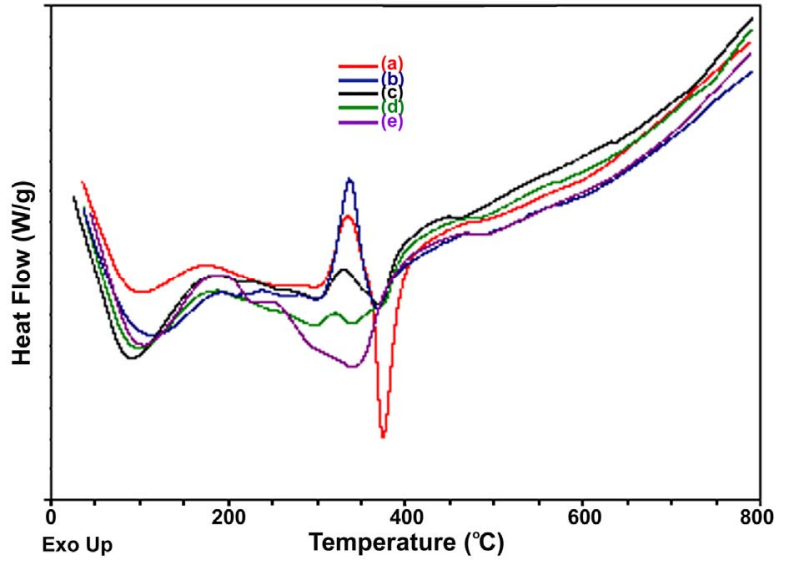

Figure 10. Heat flow curves of films prepared from different SF/G blend ratios with chlorhexidine: $3 / 0$ (a); 2/1 (b); $1 / 1$ (c); $1 / 2(d)$ and $0 / 3(e)$.



Figure 11. Releasing patterns of chlorhexidine from different films of SF/G blend ratios: 3/0 (a); 2/1 (b); 1/1 (c); 1/2 (d) and $0 / 3(e)$.

and $349^{\circ} \mathrm{C}$, respectively. Moreover, the peaks at about $200^{\circ} \mathrm{C}-350^{\circ} \mathrm{C}$ were also appeared. The heat flow curves of $\mathrm{SF} / \mathrm{G}$ blend films with and without chlorhexidine did not significantly differ. However, loading with chlorhexidine resulted to increase the temperature about $3^{\circ} \mathrm{C}$ $4^{\circ} \mathrm{C}$. The blend films showed heat flow curves in different pattern from the native films. The peaks of the films depended on the ratio of each component. It is also supported that the Eri SF and G are good compatible with formation of interaction bonds. Furthermore, adding gelatin helps to improve the flexibility of the SF film. Gelatin acted as plasticizer since it is high hydrophilic polymer.

\subsection{Releasing of Chlorhexidine}

A burst release of chlorhexidine was observed in the first 30 min of test, especially in the native SF film (Figure 11). It would be expected that the burst release occurred due to the drug on the film surfaces, and from the crystalline part of SF matrix. Chlorhexidine (diacetate) is 
a hydrophilic drug; it composed of chlorophenyl guanide and carboxylic group. It should be interacted well with the amorphous part of the SF. Therefore, the crystalline part of SF might be less interacted with the drug resulted to the burst effect of the loaded chlorhexidine [22-24]. Gelatin is a hydrophilic protein which can be interacted very well to the chlorhexidine. Therefore, the release of chlorhexidine from the native $\mathrm{G}$ film and the blend films with higher gelatin ratio were slowly than that of native $\mathrm{SF}$ or the blend film with higher SF ratio. However, the release of drug loaded in the native $G$ gradually increased when the time study increased. This might be from the dissolution of gelatin which was interacted to water.

\section{CONCLUSIONS}

The Eri SF can be dissolved by boiling in $9 \mathrm{M}$ $\mathrm{Ca}\left(\mathrm{NO}_{3}\right)_{2}$ solution with ethanol (2 ratio by mol) at $70^{\circ} \mathrm{C}$. The dissolved SF solution was then excluded impurity by dialysis against phosphate buffer $\mathrm{pH}$ 7.4. The native and the blend films have homogeneous texture under SEM observation. FTIR and thermal analysis indicated that the SF and $G$ are compatible via hydrogen bond formations. The chlorhexidine loaded did not affect on the film properties. However, the release of the chlorhexidine depended on the polarity of each polymer.

This result can be suggested that the releasing pattern of the model drug could be controlled by adjusting the ratio of the blend polymer.

\section{ACKNOWLEDGEMENTS}

The authors thank Office of the National Research Council of Thailand (NRCT) for financial support. Appreciation is also expressed to Mrs. Nual-anong Nakkong, Faculty of Science, Mahasarakham University for helping to observe SEM. Finally, we would like to thank Commission on Higher Education, Ministry of Education, Thailand for partial support of finance.

\section{REFERENCES}

[1] Piskin, E. (1995) Biodegradable polymers as biomaterials. Journal of Biomaterials Science, Polymer Edition, 6, 775795. doi:10.1163/156856295X00175

[2] Min, B.M., Lee, G., Kim, S.H., Nam, Y.S., Lee, T.S. and Park, W.H. (2004) Electrospinning of silk fibroin nanofibers and its effect on the adhesion and spreading of normal human keratinocytes and fibroblasts in vitro. Biomaterials, 25, 1289-1297. doi:10.1163/156856295X00175

[3] Mandal, B.B., Priya A.S. and Kundu, S.C. (2009) Novel silk sericin/gelatin 3-D scaffolds and 2-D films: Films: Fabrication and characterization for potential tissue engineering applications. Acta Biomaterialia, 5, 3007-3020. doi:10.1016/j.actbio.2009.03.026

[4] Servoli, E., Maniglio, D., Motta, A., Predazzer R. and
Migliaresi. C. (2005) Surface properties of silk fibroin films and their interactions with fibroblasts. Micromolecular Bioscience, 5, 1175-1183.

[5] Park, W.H., Jeong, L., Yoo, D.I. and Hudson, S. (2004) Effect of chitosan on morphology and conformation of electrospun silk fibroin nanofibers. Polymer, 45, 71517157. doi:10.1016/j.polymer.2004.08.045

[6] Nair, L.S. and Laurencin. C.T. (2007) Biodegradable polymers as biomaterial. Progress in Polymer Science, 6, 762798. doi:10.1016/j.progpolymsci.2007.05.017

[7] Foo, C.W.P. and Kaplan, D.L. (2002) Genetic engineering of fibrous proteins: Spider dragline silk and collagen. $A d-$ vanced Drug Delivery Reviews, 54, 1131-1143. doi:10.1016/S0169-409X(02)00061-3

[8] Lien, S.-M., Ko, L.-Y. and Huang, T-J. (2010) Effect of crosslinking temperature on compression strength of gelatin scaffold for articular cartilage tissue engineering. Materials Science and Engineering, C, 30, 631-635. doi:10.1016/j.msec.2010.02.019

[9] Thein-Han, W.W., Saikhun, J., Pholpramoo, C., Misra, R.D.K. and Kitiyanant, Y. (2009) Chitosan gelatin scaffolds for tissue engineering: Physico-chemical properties and biological response of buffalo embryonic stem cells and transfectant of GFP-buffalo embryonic stem cells. Acta Biomaterialia, 5, 3453-3466. doi:10.1016/j.actbio.2009.05.012

[10] Gil, E.S., Frankowski, D.J., Hudson, S.M. and Spontak, R.J. (2007) Silk fibroin membranes from solvent-crystallized silk fibroin/gelatin blends: Effects of blend and solvent composition. Materials Science Engineering, C, 27, 426-431. doi:10.1016/j.msec.2006.05.017

[11] Lee, J., Tae, G., Kim, Y.H., Park, I.S., Kim, S.-H. and Kim, S.H. (2008) The effect of gelatin incorporation into electrospun poly(L-lactide-co- $\varepsilon$-caprolactone) fibers on mechanical properties and cytocompatibility. Biomaterials, 29, 1872-1879. doi:10.1016/j.biomaterials.2007.12.029

[12] Huang, Z.M., Zhang, Y.Z., Ramakrishna, S. and Lim, C.T. (2004) Electrospinning and mechanical characterization of gelatin nanofibers. Polymer, 45, 5361-5368. doi:10.1016/j.polymer.2004.04.005

[13] Aznar-Cervantes, S., Roca, M.I., Martinez, J.G., MeseguerOlmo, L., Cenis, J.L., Moraleda, J.M. and Otero, T.F. (2012) Fabrication of conductive electrospun silk fibroin scaffolds by coating with polypyrrole for biomedical applications. Bioelectrochemistry, 85, 36-43. doi:10.1016/j.bioelechem.2011.11.008

[14] Bhardwaj, N. and Kundu, S.C. (2011) Silk fibroin protein and chitosan polyelectrolyte complex porous scaffolds for tissue engineering applications. Carbohydrate Polymer, 85, 325-333. doi:10.1016/j.carbpol.2011.02.027

[15] Fan, H., Liu, H., Toh, S.L. and Goh, J.C.H. (2008) Enhanced differentiation of mesenchymal stem cells cocultured with ligament fibroblasts on gelatin/silk fibroin hybrid scaffold. Biomaterials, 29, 1017-1027. doi:10.1016/j.biomaterials.2007.10.048

[16] Fang, Q., Chen, D., Yang, Z. and Li, M. (2009) In vitro and in vivo research on sing Antheraea pernyi silk fibroin as tissue engineering tendon scaffolds. Materials Science 
Engineering, $C, 29,1527-1534$. doi:10.1016/j.msec.2008.12.007

[17] Li, M., Tao, W., Lu, S. and Kuga, S. (2003) Compliant film of regenerated Antheraea pernyi silk fibroin by chemical crosslinking. International Journal Biological Macromolecules, 32, 159-163. doi:10.1016/S0141-8130(03)00049-7

[18] Kweon, H.Y., Um, I.C. and Park, Y.H. (2000) Thermal behavior of regenerated Antheraea pernyi silk fibroin film treated with aqueous methanol. Polymer, 45, 27752785. doi:10.1016/S0032-3861(00)00100-2

[19] Hino, T., Tanimoto, M. and Shimabayashi, S. (2003) Change in secondary structure of silk fibroin during preparation of its microspheres by spray-drying and exposure to humid atmosphere. Journal of Colloid Interface Science, 266, 68-73. doi:10.1016/S0021-9797(03)00584-8

[20] Ong-chiari, W., Srisuwan, Y., Simcheur W. and Srihanam P. (2009) Morphology, secondary structure and thermal properties of silk fibroin/gelatin blend film. Pakistan Journal of Biological Sciences, 12, 1526-1530. doi:10.3923/pjbs.2009.1526.1530

[21] Kweon, H.Y., Um, I.C. and Park, Y.H. (2001) Structural and thermal characteristics of Antheraea pernyi silk fibroin-chitosan blend film. Polymer, 42, 6651-6656. doi:10.1016/S0032-3861(01)00104-5

[22] Remuñán-López, C. and Bodmeier, R. (1997) Mechanical, water uptake and permeability properties of crosslinked chitosan glutamate and alginate films. Journal of Controlled Release, 44, 215-225. doi:10.1016/S0168-3659(96)01525-8

[23] Thakur, R.A., Florek, C.A., Kohn, J. and Michniak, B.B. (2008) Electrospun nanofibrous polymeric scaffold with targeted drug release profiles for potential application as wound dressing. International Journal of Pharmaceutics, 364, 87-93. doi:10.1016/j.ijpharm.2008.07.033

[24] Zeng, J., Yang, L., Liang, Q., Zhang, X., Guan, H., Chen, $X$. and Jing, X. (2005) Influence of the drug compatibility with polymer solution on the release kinetics of electrospun fiber formation. Journal of Controlled Release, 105, 43-51. doi:10.1016/j.jconrel.2005.02.024 